Harrison R, Spearpoint M J. Physical scale modelling of adhered spill plume entrainment. Fire Safety Journal, Vol.45, No.3, p.149-158, http://dx.doi.org/10.1016/j.firesaf.2010.02.005, 2010.

\title{
Physical Scale Modelling of Adhered Spill Plume Entrainment
}

\author{
ROGER HARRISON AND MICHAEL SPEARPOINT* \\ Department of Civil and Natural Resources Engineering, University of Canterbury, New Zealand
}

\begin{abstract}
This work provides new experimental data to characterise entrainment of air into adhered thermal spill plumes using physical scale modelling. For the two-dimensional plume, the rate of entrainment with respect to height of rise is approximately half that of an equivalent twodimensional balcony spill plume. For the three-dimensional plume, the rate of entrainment appears to be linked to the plume behaviour, which has been characterised in terms of the width and depth of the layer flow below the spill edge. In general, a layer flow below the spill edge that is shallow compared to its width will tend to adhere to the wall above the opening compared to flows whose depth approaches its width. This work proposes new empirical entrainment design formulae that have been developed on a more general basis compared to existing methods.
\end{abstract}

KEYWORDS: adhered spill plume, smoke management, entrainment, scale modelling

\section{INTRODUCTION}

In the design of smoke management systems, consideration is often given to entrainment of air into a smoke flow from a compartment opening that subsequently spills and then rises into an adjacent atrium void. When there is a vertical wall projecting above the compartment opening (without a balcony or horizontal projection) the resulting plume will typically adhere to the wall above the opening as it rises. This type of plume is commonly known as an adhered spill plume (see Figure 1). Plumes that do not include entrainment into its ends are known as twodimensional (2-D) plumes and those that include end entrainment are known as threedimensional (3-D) plumes. There is limited data on entrainment into adhered plumes with a simplified design formula developed by Poreh et al. [1] for the 2-D plume from $1 / 10^{\text {th }}$ physical scale model experiments. There are no robust simplified formulae to predict entrainment for the 3-D adhered plume, however, CIBSE [2] provide an approximate solution for this scenario using

\footnotetext{
"Corresponding author: michael.spearpoint@canterbury.ac.nz; tel.: +64 (0)3 364 2237; fax: +64 (0)3 3642758
} 
reduced scale experimental data obtained by Hansell et al. [3]. A review of existing simple calculation methods for the adhered plume is given by Harrison and Spearpoint [4]. The more complicated BRE spill plume method [5] provides a prediction of both 2-D and 3-D adhered plume entrainment.

This paper provides new experimental data to characterise entrainment by varying the type of plume, the width of the fire compartment opening, fire size and height of rise. New empirical design formulae are proposed from the analysis.

\section{PHYSICAL SCALE MODELLING}

The approach of physical scale modelling is well established and has been used in many studies of smoke movement in buildings. The approach described in this article was primarily developed at the Fire Research Station in the UK $[6,7]$ and typically takes the form of reduced scale fires within a physical model. The approach is also described by Klote and Milke [8] and is included in NFPA 92B [9]. Measurements can be extrapolated to full scale using the appropriate scaling laws. To ensure that the results can be extrapolated to full scale, the physical scale model used in this study was designed to meet the scaling principles set out by Thomas et al. [6]. This is effectively a modified Froude number scaling and requires that the equivalent flows are fully turbulent on both full and model scale. Turbulent flow is typically achieved for flows with Reynolds numbers $\geq 4000$ [10]. In this series of experiments the Reynolds number of the horizontally flowing layer flows below the spill edge were determined, with values to ranging between approximately 7000 and 12500 . This demonstrated that the significant flows were fully turbulent and that scaling laws could be applied with confidence for the range of flows generated in the physical scale model.

\section{THE EXPERIMENT}

\section{The physical scale model}

Figure 2 shows the $1 / 10^{\text {th }}$ physical scale model used. The model simulated a fire within a room adjacent to an atrium void and consisted of two main units, the fire compartment and a smoke collecting hood. A detailed specification of the model is given by Harrison [11]. The width of the 
fire compartment opening was varied by inserting walls of $25 \mathrm{~mm}$ thick Ceramic Fibre Insulation (CFI) board of equal width at either end. The walls had widths of $0.1,0.2,0.3$ and $0.4 \mathrm{~m}$. A steady state fire source was generated by supplying Industrial Methylated Spirits (IMS) into a metal tray within the fire compartment at a controlled and measured rate. The tray was located at the rear of the fire compartment and had dimensions of 0.25 by 0.25 by $0.015 \mathrm{~m}$ high. The fuel was supplied to the tray continuously via a fuel reservoir, flowmeter and copper tubing. The hot gases from the fire and the subsequent spill plume were visualised by injecting smoke from a commercial smoke generator into the fire compartment. The model was designed such that the walls of the smoke collecting hood could freely move in a vertical direction within a supporting steel frame. This enabled the base of each wall to be moved independently to just below the base of the smoke layer in the hood allowing unrestricted fresh air to be entrained into the rising plume. However, the wall of the collecting hood directly above the fire compartment opening was lowered so that it extended from the top of the compartment and beyond the ceiling of the hood. This simulated a vertically projecting wall above the spill edge as required for the adhered plume scenario. A section of steel reinforcing mesh ( $75 \mathrm{~mm}$ by $75 \mathrm{~mm}$ grid size) was hung next to one wall of the collecting hood to provide a point of reference for visual observations for the plume behaviour.

For those experiments which examined 2-D plumes, screens were suspended from the ceiling of the hood, in line with each side of the fire compartment opening to prevent air entering the ends of the plume over its full height of rise. The screens were moveable and vertically projected $0.3 \mathrm{~m}$ below and $1.1 \mathrm{~m}$ above the spill edge.

One of the key parameters in this study was the height of rise of the plume. A mechanical smoke exhaust system from the hood consisted of a $0.44 \mathrm{~m}$ diameter bifurcated fan attached to the hood exhaust vent using temperature resistant flexible ducting. The fan speed was controllable allowing a fixed exhaust rate to be specified to vary the height of rise of the plume to be examined. 


\section{Instrumentation and measurements}

Gas temperatures were measured using $0.5 \mathrm{~mm}$ diameter K-type thermocouples positioned at various locations in the model as follows: two columns of 15 thermocouples within the smoke collecting hood; one column of 18 thermocouples located centrally beneath the spill edge; one column of 18 thermocouples above the spill edge along the centreline of the plume, $5 \mathrm{~mm}$ from the wall of the collecting hood above the spill edge; an array of five thermocouples in the throat of the exhaust vent; one thermocouple located centrally within the smoke exhaust duct, $5.0 \mathrm{~m}$ downstream of the exhaust vent; two thermocouples, one located next to each of two pitot-static tubes, when measuring velocity profiles of the smoke layer below the spill edge.

A perforated gas sampling tube was located across the horizontal diameter of the exhaust duct approximately $5.0 \mathrm{~m}$ downstream of the vent in the smoke collecting hood. This enabled measurement of the $\mathrm{CO}_{2}$ gas concentration of the flow in the duct to be made using an infra red gas analyser (Siemens, Ultramat 6 , accuracy $\pm<1 \%$ ). The mass flow rate of gases entering the gas layer in the smoke collecting hood and therefore leaving the hood, was found by using a $\mathrm{CO}_{2}$ tracer gas technique and calculation method described by Marshall [7]. Vertical velocity profiles of the gas layer flow below the spill edge were made using two pitot-static tubes. The pitot-tubes were each located a distance of one-third of the compartment opening width from each side of the opening. Each pitot-tube was connected to a sensitive differential pressure transducer (Furness Controls FCO 012, \pm 1 and \pm 10 Pa full scale range, accuracy $\pm 0.25 \%$ ). Velocity measurements were made every $10 \mathrm{~mm}$ below the spill edge until the base of the smoke layer was reached. This measurement, in addition to the temperature profiles, enabled the mass flow rate and convective heat flow rate of the gas layer flow below the spill edge (i.e. $\dot{m}_{s}$ and $\dot{Q}_{c}$ ) to be determined.

\section{Parameter variation}

A total of 110 experiments were carried out. The majority of experiments examined a 3-D adhered spill plume. The total heat release rate of the fire was varied with fire sizes of 5,10 and $15 \mathrm{~kW}$ examined. This equates to a fire size of $1.6,3.2$ and $4.7 \mathrm{MW}$ respectively for a full scale equivalent using the scaling laws. Varying the total heat output of the fire in turn varied the mass 
flow rate, convective heat flow rate and depth of the gas layer below the spill edge. The width of the fire compartment opening was varied with widths of $0.2,0.4,0.6,0.8$ and $1.0 \mathrm{~m}$ examined. The conditions studied were chosen to provide a range of flows below the spill edge (i.e. from relatively cool, shallow and wide layer flows to hot, deep and narrow flows) which could conceivably be generated from a range of possible geometries upstream of the spill edge (e.g. the presence of a downstand fascia). The total amount of entrainment upstream of the spill edge can be determined separately using existing guidance [e.g. 2, 5, 12] depending upon the geometry in question and these effects are not specifically addressed in this study. The height of rise of plume above the spill edge was also varied with six different heights examined between 0 to $1.25 \mathrm{~m}$ for each combination of opening width and fire size examined.

Selected experiments were carried out to examine 2-D adhered spill plumes to confirm and extend the findings from previous work. For these experiments, the height of rise of plume above the spill edge was varied with five different heights examined between 0 to $1.10 \mathrm{~m}$. The width of the fire compartment opening was varied with widths of $0.2,0.4,0.6,0.8$ and $1.0 \mathrm{~m}$ examined. The total heat output of the fire remained fixed at $10 \mathrm{~kW}$ for the experiments without end entrainment.

\section{RESULTS AND DISCUSSION}

\section{Analysis}

The analysis of the experimental results utilises the same entrainment models that have been developed for the analysis of 2-D balcony spill plumes, with the difference in entrainment accounted for in the empirical entrainment coefficient(s). Thomas et al. [13] used a rigorous dimensional analysis to develop a simplified spill plume formula in the form given by,

$$
\frac{\dot{m}_{p, 2 D}^{\prime}}{\dot{Q}_{c}^{\prime}}=\gamma \frac{z_{s}}{\dot{Q}_{c}^{\prime 2 / 3}}+\delta \frac{\dot{m}_{s}^{\prime}}{\dot{Q}_{c}^{\prime}}+\varepsilon
$$

Poreh et al. [14] deduced the following simplified formula by assuming a virtual line source below the spill edge, given by,

$$
\frac{\dot{m}_{p, 2 D}^{\prime}-\dot{m}_{s}^{\prime}}{\dot{Q}_{c}^{\prime}}=C\left(\frac{z_{s}+d_{s}}{\dot{Q}_{c}^{\prime 2 / 3}}\right)
$$


These methods will be used to analyse the experimental data from this study for both the 2-D and 3-D adhered plume.

\section{The 2-D adhered spill plume}

For all of the 2-D plume experiments the plume behaviour was observed to be similar to that shown in Figure 1, where the horizontal flow of gases within the fire compartment flow from the opening, rotate at the spill edge (i.e. the top of the compartment opening) and rise as a 2-D plume between the screens used to prevent entrainment into its ends. Previous work by Poreh et al. [1] provide limited experimental data for 2-D adhered spill plumes, they correlated the data according to Equation 2 to determine that,

$$
\frac{\dot{m}_{p, 2 D}^{\prime}-\dot{m}_{s}^{\prime}}{\dot{Q}_{c}^{\prime}}=0.075\left(\frac{z_{s}+d_{s}}{\dot{Q}_{c}^{\prime 2 / 3}}\right)
$$

Equation 3 was determined from fires with $\dot{Q}_{c}$ ranging between 2.9 to $11.9 \mathrm{~kW}$. However, the width of the opening $W_{s}$ was fixed in these experiments at $0.91 \mathrm{~m}$. Therefore, in this study a selected number of experiments were carried out to complement the Poreh et al. data to determine if Equation 3 applies generally for a range of $W_{s}$. Figure 3 shows the data obtained from this study and the data given by Poreh et al., plotted in a form according to Equation 2. A line representing Equation 3 is also shown.

Figure 3 shows the data from this study being broadly in line with the previous data, although the Poreh et al. data exhibits much greater scatter. The data from this work correlates to a line (through the origin) such that $C=0.080$ with a standard error of 0.001 . The Poreh et al. data correlates to a line with $C=0.072$ with standard error of 0.003 . Performing linear regression on the complete data set gives $C=0.074$ with a standard error of 0.002 , which is consistent with Equation 3 given by Poreh et al. Therefore it appears that Equation 3 applies generally and is independent of $\dot{Q}_{c}$ and $W_{s}$. However, considering the greater amount of scatter in the Poreh et al. data compared to the data obtained from this study it would seem reasonable to describe 
Equation 3 by the following equation for the 2-D adhered plume (i.e. $C=0.08$ ) for design purposes such that

$$
\frac{\dot{m}_{p, 2 D}^{\prime}-\dot{m}_{s}^{\prime}}{\dot{Q}_{c}^{\prime}}=0.08\left(\frac{z_{s}+d_{s}}{\dot{Q}_{c}^{\prime 2 / 3}}\right)
$$

The characteristic slope of the linear relationship given by Equation 4 (i.e. $C$ ) represents the rate of entrainment above the spill edge. The value of $C$ is half that of an equivalent 2-D balcony spill plume (i.e. $C=0.16$ ) [15] and gives a result consistent with the findings of previous work (i.e. reference 1 and 3 ). This is unsurprising considering that entrainment only occurs into one side of a 2-D adhered plume, compared to two sides in a 2-D balcony spill plume. These data can also be analysed according to the Thomas et al. method [13] given by Equation 1, as shown in Figure 4. Using multiple linear regression the data obtained from this study correlates to

$$
\frac{\dot{m}_{p, 2 D}^{\prime}}{\dot{Q}_{c}^{\prime}}=0.083 \frac{z_{s}}{\dot{Q}_{c}^{\prime 2 / 3}}+1.35 \frac{\dot{m}_{s}^{\prime}}{\dot{Q}_{c}^{\prime}}-0.0012
$$

The standard error of $\gamma$ (i.e. the 0.083 ) is 0.003 . Similarly, the Poreh et al. data correlates to

$$
\frac{\dot{m}_{p, 2 D}^{\prime}}{\dot{Q}_{c}^{\prime}}=0.076 \frac{z_{s}}{\dot{Q}_{c}^{\prime 2 / 3}}+0.645 \frac{\dot{m}_{s}^{\prime}}{\dot{Q}_{c}^{\prime}}+0.0068
$$

The standard error of $\gamma$ is 0.004 . The complete data set correlates according to

$$
\frac{\dot{m}_{p, 2 D}^{\prime}}{\dot{Q}_{c}^{\prime}}=0.081 \frac{z_{s}}{\dot{Q}_{c}^{\prime 2 / 3}}+0.825 \frac{\dot{m}_{s}^{\prime}}{\dot{Q}_{c}^{\prime}}+0.0029
$$

The standard error of $\gamma$ is 0.002 . Therefore, the regression coefficient $\gamma$ which represents the rate of entrainment above the spill edge can be considered to be the same (to within one standard error) with a value of 0.08 , which is identical to the equivalent regression coefficient (i.e. $C$ ) proposed in Equation 4.

A general expression to describe the decoupled entrainment below the height of the spill edge (i.e. $\dot{m}_{p}$ at $z_{s}=0$ ) has been characterised by Harrison and Spearpoint [15] and is given by, 
$\frac{\dot{m}_{p, z_{s}=0}^{\prime}}{\dot{Q}_{c}^{\prime}}=1.34\left(\frac{\dot{m}_{s}^{\prime}}{\dot{Q}_{c}^{\prime}}\right) \Rightarrow \dot{m}_{p, z_{s}=0}=1.34 \dot{m}_{s}$

Therefore it seems reasonable to describe the entrainment below the spill edge with regression coefficients of $\delta=1.34$ and $\varepsilon=0$. Hence, combining these with the regression coefficient describing the entrainment above the spill edge (i.e. $\gamma$ ), Equation 9 is proposed as a new simplified design formula for the 2-D adhered plume such that

$$
\frac{\dot{m}_{p, 2 D}^{\prime}}{\dot{Q}_{c}^{\prime}}=0.08 \frac{z_{s}}{\dot{Q}_{c}^{\prime 2 / 3}}+1.34 \frac{\dot{m}_{s}^{\prime}}{\dot{Q}_{c}^{\prime}} \quad \Rightarrow \dot{m}_{p, 2 D}=0.08 \dot{Q}_{c}^{1 / 3} W_{s}^{2 / 3} z_{s}+1.34 \dot{m}_{s}
$$

\section{The 3-D adhered spill plume}

\section{Plume behaviour}

The following description of plume behaviour is for 3-D plumes generated from a spill edge with a flat ceiling and does not apply when there is a downstand fascia at the edge. Contrary to the 2-D adhered plume, the behaviour of the 3-D adhered plume was highly dependent on the width of the fire compartment opening. Plumes generated from a wide opening (e.g. $W_{s}=1.0 \mathrm{~m}$ ) were observed to adhere to the wall above almost immediately (see Figure 5a). Entrainment of air occurred into the front side of the plume exposed to ambient air and also into the free ends of the plume. Figure $5 \mathrm{~b}$ shows that the lateral extent of the plume tended to narrow slightly, before broadening above as end entrainment became more significant (the edge of the plume is marked with a dashed line).

Plumes generated from intermediate width openings (e.g. $W_{s}=0.6$ to $0.8 \mathrm{~m}$ ) were initially observed to horizontally project beyond the opening, before curling back and reattaching to the wall above, after which the plume adhered to the wall (see Figure 6a). The height of reattachment above the spill edge tended to increase as $W_{s}$ decreased and when the fire size and depth of the layer below the spill edge increased. Entrainment of air was observed into the front and rear side of the plume (via the ends) in the region where it was detached and also into the free ends. After the plume had reattached to the wall above, entrainment only occurred into the front side of the plume and the free ends. The mechanism causing reattachment of the plume to the wall above 
the opening is described by Zukoski [16] and is due to the decrease in static pressure between the wall and the plume (in the region where the plume is detached). This reduction in pressure occurs when the supply of ambient air cannot be easily supplied to the rear of the plume in this region and the entrainment process causes the static pressure to fall close to the wall. This low pressure region causes the plume to be pulled back toward the wall and reattachment occurs. This behaviour is more commonly known as the Coanda effect. Figure $6 \mathrm{~b}$ shows that the lateral extent of the plume narrowed in the region where the plume was detached from the wall due to entrainment into the rear of the plume via the ends (the edge of the plume is marked with a dashed line). The plume was observed to broaden above the point of reattachment, most likely due to end entrainment becoming more significant, analogous to recent findings by Harrison and Spearpoint [15] on the broadening of balcony spill plumes.

Plumes generated from narrow width openings (see Figure 7a) were observed to project beyond the opening and not reattach to the wall above, with entrainment occurring on both sides of the plume and the free ends over the full height of rise. This is most likely due to the combined effect of the increased momentum of the flow from the opening and the relative narrow width of the plume are not enough to create a small enough pressure drop at the rear of the plume and the Coanda effect does not occur. Figure $7 \mathrm{~b}$ shows that from a front view the lateral extent of the plume tended to broaden above the spill edge (the edge of the plume is marked with a dashed line), again likely to be due to the contribution of end entrainment.

The general behaviour described above is similar to that observed in previous work which examined the trajectory of flames from windows from post-flashover fires. This was first studied experimentally by Yokoi [17] and later studied numerically by Galea et al. [18]. These studies highlighted that the behaviour of the flame plumes from windows were dependent upon the geometry of the window. When the window was narrow compared to its height, the flame plumes tended to project beyond the opening and sometimes reattach to a wall above. However, for windows that were wide compared to their height, the flames adhered immediately to the wall above the window. Yokoi characterised the behaviour of window flame plumes by considering the characteristics of the flow at the window opening. A geometric parameter was defined to describe 
the plume behaviour from the window, which was the ratio of twice the width of the opening to the height of the opening. Zukoski [16] suggests that as the Yokoi experiments were for post flashover fires, the depth of the outflow from the window was approximately half the window height. Hence, this geometric parameter can be considered to be the ratio of the width over the depth of the out flow (i.e. width of the window over half the window height). The behaviour of the 3-D adhered plumes observed in this work can be characterised by following a similar analysis to that of Yokoi, by considering the out flowing layer in terms of the width and depth of the layer flow below the spill edge (i.e. $W_{s}$ and $d_{s}$ ). The height at which the plume first reattaches to the wall above the spill edge (i.e. $z_{\text {attach }}$ ) was determined from visual observations. In an attempt to describe the plume behaviour beyond the spill edge, Figure 8 shows a plot in non-dimensional form of $z_{\text {attach }} / W_{s}$ with respect to $W_{s} / d_{s}$. Figure 8 shows a clear relationship between $z_{\text {attach }} / W_{s}$ and $W_{s} / d_{s}$ which suggests that the behaviour of the 3-D adhered plume is dependent on the characteristics of the layer flow below the spill edge (in terms of $W_{s}$ and $d_{s}$ ). In general, a layer flow below the spill edge that is shallow compared to its width will tend to adhere to the wall above the opening compared to flows whose depth approaches its width, and this is supported by the visual observations. Plumes did not reattach to the wall above the spill edge when $W_{s} / d_{s} \leq 3$. When $W_{s} / d_{s}>3$ the plume reattaches to the wall above the spill edge and $z_{\text {attach }}$ can be determined from the line of best fit through the data described by the following power law

$$
\frac{z_{\text {attach }}}{W_{s}}=8\left(\frac{W_{s}}{d_{s}}\right)^{-2} \Rightarrow z_{\text {attach }}=\frac{8 d_{s}^{2}}{W_{s}}
$$

\section{Entrainment correlation}

To develop a general expression to describe 3-D adhered spill plume entrainment, the following analysis examines the total amount of entrainment above the spill edge, as the decoupled entrainment below the height of the spill edge (i.e. $\dot{m}_{p}$ at $z_{s}=0$ ) has already been characterised by Harrison and Spearpoint [15] and given by Equation 8 . The generalised form of the method by Thomas et al. [13] is used in the analysis to be consistent with approach used by Harrison and Spearpoint [15] for the analysis of 3-D balcony spill plumes. 
To decouple the entrainment above the spill edge, the measured mass flow rates were modified by subtracting $\dot{m}_{p}$ at $z_{s}=0$ for each $W_{s}$ and $\dot{Q}_{t}$ examined. Thus, for each $W_{s}$, the data set passes through the origin. Figure 9 shows a plot of all the data in a form consistent with the dimensional analysis by Thomas et al. describing the decoupled entrainment above the spill edge.

Figure 9 shows some scatter of the data which appears to be dependent on $W_{s}$. The slope of the line through each data set (i.e. $\gamma$ ) represents the rate of entrainment above the spill edge. For each value of $W_{s}$ examined $\gamma$ appears to increase as $W_{s}$ decreases. The data generally exhibits linearity, although there is some scatter in the data in some cases due to the entrainment behaviour of the plume varying with respect to height of rise (e.g. when the plume detaches and then reattaches to the wall above, and due to narrowing of the plume). Figure 9 indicates that plumes generated from narrower openings (that tend to detach from the wall) entrain air at a greater rate with respect to height compared to plumes generated from wider openings (that tend to adhere to the wall). This is unsurprising when considering the plume behaviour described above and it appears that the amount of entrainment into the plume is specifically linked to the plume behaviour. The results were therefore correlated with respect to $W_{s} / d_{s}$ as the above analysis demonstrates that this non-dimensional parameter can be successfully used to describe the plume behaviour. Therefore, linear regression was performed to determine the value of $\gamma$ for each $W_{s} / d_{s}$ examined (see Figure 10).

Figure 10 shows that the values of $\gamma$ determined for each $W_{s} / d_{s}$ examined collapse to the relationship given by

$\gamma=0.284\left(\frac{W_{s}}{d_{s}}\right)^{-0.48}$ 
The standard errors of the regression coefficients 0.284 and -0.48 are 0.02 and 0.04 respectively. Therefore, considering there was some scatter in the data in some cases, it seems reasonable and convenient to be slightly conservative and simplify Equation 11 to

$\gamma=0.3\left(\frac{W_{s}}{d_{s}}\right)^{-1 / 2}$

Equation 12 indicates that for a layer flow below the spill edge that is shallow compared to its width (e.g. $\left.W_{s} / d_{s} \approx 12\right)$ where the subsequent spill plume adheres almost immediately to the wall above, $\gamma \approx 0.09$ which is approximately half that of an equivalent balcony spill plume where $\gamma \approx 0.20$ [15]. For a layer flow below the spill edge whose depth is similar to its width (e.g. $W_{s} / d_{s} \approx 1.0$ ), where the subsequent plume did not reattach to the wall, $\gamma \approx 0.3$. This value of $\gamma$ is comparable to that of an equivalent balcony spill plume, where $\gamma \approx 0.32$ [15]. Intermediate width openings give rise to values of $\gamma$ between these upper and lower bounds. Therefore, it appears that the rate of entrainment is dependent on the behaviour of the plume, which is in turn dependent on the characteristics of the layer flow at the opening. There is a limit to the use of Equation 12 as it is expected that for large $W_{s} / d_{s}$ the value of $\gamma$ should approach that of the 2-D spill plume (i.e. 0.08). However, Equation 12 predicts values of $\gamma$ below 0.08 for $W_{s} / d_{s}>13$, therefore the following limit applies to its use such that

$$
\left(\frac{W_{s}}{d_{s}}\right) \leq 13
$$

Since $\gamma$ represents the total rate of entrainment above the spill edge (including end entrainment), the mass flow rate of gases in the plume above the spill edge can by described by

$$
\frac{\dot{m}_{p, 3 D}^{\prime}-m_{p, z_{s}=0}^{\prime}}{\dot{Q}_{c}^{\prime}}=\gamma \frac{z_{s}}{\dot{Q}_{c}^{\prime 2 / 3}}=0.3\left(\frac{W_{s}}{d_{s}}\right)^{-1 / 2}\left(\frac{z_{s}}{\dot{Q}_{c}^{\prime 2 / 3}}\right)
$$

A new design for the 3-D adhered plume can be developed by summing the decoupled entrainment both above and below the spill edge [i.e. Equations 14 and 8] to give Equation 15 which is consistent with the dimensional analysis by Thomas et al. and only applies when there is a flat ceiling at the spill edge. 


$$
\begin{aligned}
& \frac{\dot{m}_{p, 3 D}^{\prime}}{\dot{Q}_{c}^{\prime}}=0.3\left(\frac{W_{s}}{d_{s}}\right)^{-1 / 2}\left(\frac{z_{s}}{\dot{Q}_{c}^{\prime 2 / 3}}\right)+1.34 \frac{\dot{m}_{s}^{\prime}}{\dot{Q}_{c}^{\prime}} \\
& \Rightarrow \dot{m}_{p, 3 D}=0.3 \dot{Q}_{c}^{1 / 3} W_{s}^{1 / 6} d_{s}^{1 / 2} z_{s}+1.34 \dot{m}_{s}
\end{aligned}
$$

For flows where $W_{s} / d_{s}>13$, then Equation 9 for the 2-D plume should be used instead.

At high heights of rise of plume, the effect of end entrainment will cause the plume to be more axisymmetric in nature and Equation 15 will no longer apply. Therefore, as a conservative estimate, the following upper height limit developed by Harrison [11] for the 3-D balcony spill plume is proposed until further work is carried out to determine a suitable limit for the 3-D adhered plume. Therefore, Equation 15 applies when $z_{s} \leq z_{\text {trans }}$, where,

$$
z_{\text {trans }}=3.4\left(W_{s}^{2 / 3}+1.56 d_{s}^{2 / 3}\right)^{3 / 2}
$$

The simplified formulae proposed in this paper require various input parameters. Some parameters such as $W_{s}$ and $z_{s}$ are easily determined from the given geometry question. $\dot{Q}_{c}$ is determined by assuming a suitable convective component of the gas flow based on the type of fuel assumed in the design fire. $\dot{m}_{s}$ and $d_{s}$ are dependent upon the specific geometry upstream of the spill edge and may involve a single or many entrainment processes. Guidance to determine $\dot{m}_{s}$ and $d_{s}$ is given by Morgan et al. [5], CIBSE [2] or from any other suitable methods. More detailed guidance on suitable input parameters for these formulae is given by Harrison [11].

\section{CONCLUSIONS}

This work has demonstrated that the existing simplified design formula for the 2-D adhered spill plume appears to apply generally for the range of $\dot{Q}_{c}$ and $W_{s}$ examined in the experiments. The rate of entrainment with respect to height above the spill edge is approximately half that of an equivalent 2-D balcony spill plume. The following is proposed as a new simplified design formula for the 2-D adhered plume,

$\dot{m}_{p, 2 D}=0.08 \dot{Q}_{c}^{1 / 3} W_{s}^{2 / 3} z_{s}+1.34 \dot{m}_{s}$ 
The behaviour of the 3-D adhered plume has been characterised in terms of the width and depth of the layer flow below a flat spill edge (i.e. $W_{s}$ and $d_{s}$ ). In general, a layer flow below the spill edge that is shallow compared to its width will tend to adhere to the wall above the opening compared to flows whose depth approaches its width. For $W_{s} / d_{s}>3$, the height at which the plume first reattaches to the wall above the spill edge can be determined from the following empirical relationship given by

$$
z_{\text {attach }}=\frac{8 d_{s}^{2}}{W_{s}}
$$

Plumes did not reattach to the wall above the spill edge when $W_{s} / d_{s} \leq 3$. The amount of entrainment into the 3-D adhered plume is specifically linked to the plume behaviour, such that plumes generated from narrower openings (that tend to detach from the wall) entrain air at a greater rate with respect to height compared to plumes generated from wider openings (that tend to adhere to the wall). The following is proposed as a new simplified design formula for the 3-D adhered plume with a flat ceiling at the spill edge,

$\dot{m}_{p, 3 D}=0.3 \dot{Q}_{c}^{1 / 3} W_{s}^{1 / 6} d_{s}^{1 / 2} z_{s}+1.34 \dot{m}_{s}$ with the limit, $\left(\frac{W_{s}}{d_{s}}\right) \leq 13$

For flows where $W_{s} / d_{s}>13$, then the proposed simplified formula for the 2-D adhered plume should be used instead. As a conservative estimate, the following upper height limit developed by Harrison [11] for the 3-D balcony spill plume is proposed until further work is carried out to determine a suitable upper limit for the 3-D adhered plume. Therefore, the proposed formula for the 3-D adhered plume applies when $z_{s} \leq z_{\text {trans }}$, where,

$$
z_{\text {trans }}=3.4\left(W_{s}^{2 / 3}+1.56 d_{s}^{2 / 3}\right)^{3 / 2}
$$




\section{ACKNOWLEDGEMENTS}

The authors would like to thank the following: Education New Zealand, for awarding the lead author a New Zealand International Doctoral Research Scholarship. The National Fire Protection Association for awarding the lead author the David B. Gratz Scholarship. Bob Wilsea-Smith and Grant Dunlop of the University of Canterbury, for their help with the design and construction of the experimental apparatus. The New Zealand Fire Service Commission for their continued support of the Fire Engineering programme at the University of Canterbury.

\section{NOMENCLATURE}

Symbol

C

$d_{s}$

$\dot{m}_{s}$

$\dot{m}_{p, 2 D}$

$\dot{m}_{p, 3 D}$

$\dot{Q}_{c}$

$\dot{Q}_{t}$

$W$

$z_{\text {attach }}$

$z_{s}$

$z_{\text {trans }}$

\section{Description}

Entrainment coefficient in Equation $2\left(\mathrm{~kg} \mathrm{~m}^{1 / 3} \mathrm{~s}^{-1} \mathrm{~kW}^{-1 / 3}\right)$

Depth of gas layer below the spill edge $(m)$

Mass flow rate of gases in the layer flow below the spill edge $\left(\mathrm{kgs}^{-1}\right)$

Mass flow rate of gases in the 2-D plume at an arbitrary height of rise $\left(\mathrm{kgs}^{-1}\right)$

Mass flow rate of gases in the 3-D plume at an arbitrary height of rise $\left(\mathrm{kgs}^{-1}\right)$

Convective heat flow of gases below the spill edge $(\mathrm{kW})$

Total heat output of the fire $(\mathrm{kW})$

Lateral extent of gas flow below the spill edge $(\mathrm{m})$

Height of rise of the plume above the spill edge at which the plume first reattaches to the wall above $(\mathrm{m})$

Height of rise of the plume above the spill edge to the smoke layer base in the reservoir $(\mathrm{m})$

Height of rise of plume above the spill edge where there is a transition in the rate of entrainment to that of an axisymmetric plume $(\mathrm{m})$ 


$\begin{array}{ll}\text { Greek symbol } & \text { Description } \\ \gamma & \text { Regression coefficient } \\ \delta & \text { Regression coefficient } \\ \varepsilon & \text { Regression coefficient }\end{array}$

\section{REFERENCES}

1. Poreh M, Marshall N R and Regev A. "Entrainment by adhered two-dimensional plumes". Fire Safety Journal, vol. 43, no. 5, pp 344-350, July 2008.

2. Chartered Institution of Building Services Engineers, CIBSE Guide Volume E: Fire Engineering, London, CIBSE, 2003.

3. Hansell G O, Morgan H P and Marshall N R. "Smoke Flow Experiments in a Model Atrium". Building Research Establishment Occasional Paper, OP 55, 1993.

4. Harrison R and Spearpoint M J. "A review of Simple Entrainment Calculation Methods for the Thermal Spill Plume". International Journal on Engineering Performanced-Based Fire Codes. Accepted for publication, July 2009.

5. Morgan H P, Ghosh B K, Garrad G, Pamlitschka R, De Smedt J-C and Schoonbaert L R. "Design methodologies for smoke and heat exhaust ventilation”. BRE Report 368, 1999.

6. Thomas P H, Hinkley P L, Theobald C R and Simms D L. "Investigations into the Flow of Hot Gases in Roof Venting". Fire Research Technical Paper No 7, London, The Stationary Office, 1963.

7. Marshall N R. "The Behaviour of Hot Gases Flowing within a Staircase". Fire Safety Journal, vol. 9, no. 3, 1985, pp 245-255.

8. Klote J H and Milke J A. "Principles of Smoke Management". American Society of Heating, Refrigerating and Air-conditioning Engineers, Atlanta, GA, 2002.

9. National Fire Protection Association. "Smoke Management Systems in Malls, Atria and Large Areas". (2009 edition). Publication No.92B. Quincy, MA, 2009.

10. Massey B S. "Mechanics of fluids". Van Nostrand Reinhold Company, London, 1990.

11. Harrison R. "Entrainment of Air into Thermal Spill Plumes". Doctor of Philosophy in Fire Engineering, University of Canterbury, New Zealand, 2009. 
12. Harrison R and Spearpoint M. "The Balcony Spill Plume: Entrainment of air into a flow from a compartment opening to a higher projecting balcony". Fire Technology, vol. 43, no. 4, pp $301-317,2007$.

13. Thomas P H, Morgan H P and Marshall N R. "The Spill Plume in Smoke Control Design". Fire Safety Journal, vol. 30, no. 1, pp 21-46, 1998.

14. Poreh M, Morgan H P, Marshall N R and Harrison R. "Entrainment by Two Dimensional Spill Plumes in Malls and Atria". Fire Safety Journal, vol. 30, no.1, pp 1-19, 1998.

15. Harrison R and Spearpoint M. "Characterisation of balcony spill plume entrainment using physical scale modelling". Proceedings of the 9th Symposium of the International Association of Fire Safety Science, Karlsruhe, Germany, pp 727-738, 2008.

16. Zukoski E E. "Properties of fire plumes". Combustion Fundamentals of Fire, Cox G, Editor. Academic Press, London, 1995.

17. Yokoi S. "Study on the prevention of fire spread by hot upward current". Building Research Institute Report 34, Japan, 1960.

18. Galea E R, Berhane D and Hoffmann N. "CFD analysis of fire plumes emerging from windows in high-rise buildings". Proceedings of Fire Safety by Design, vol. 3, University of Sunderland, pp 111-120, 1995. 


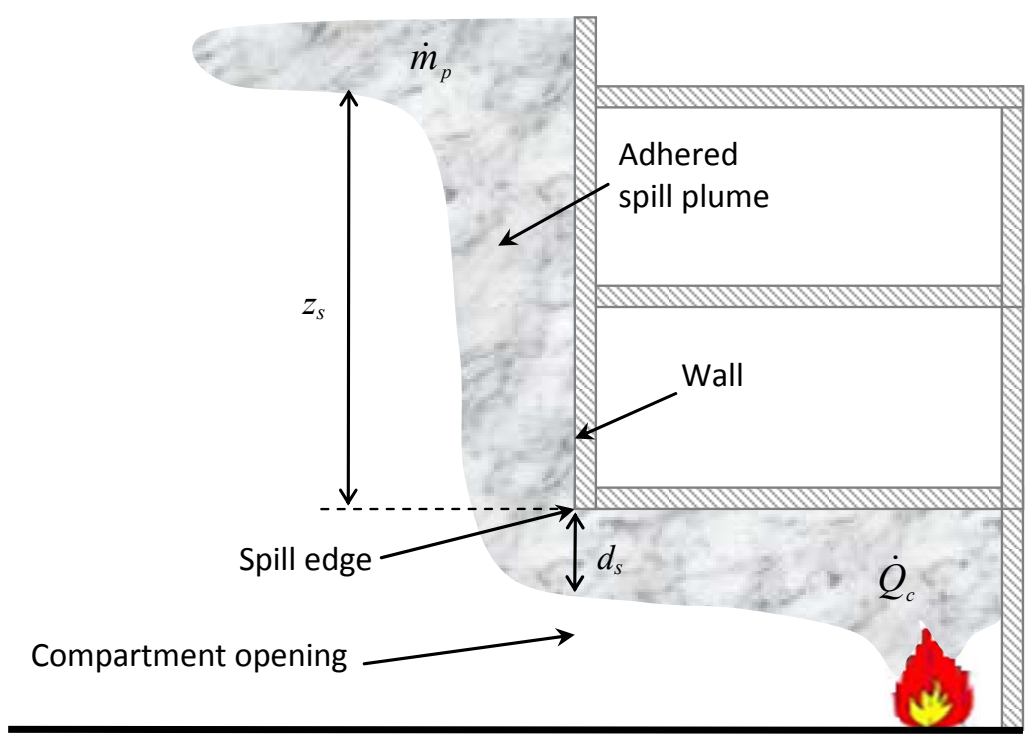

a) Section

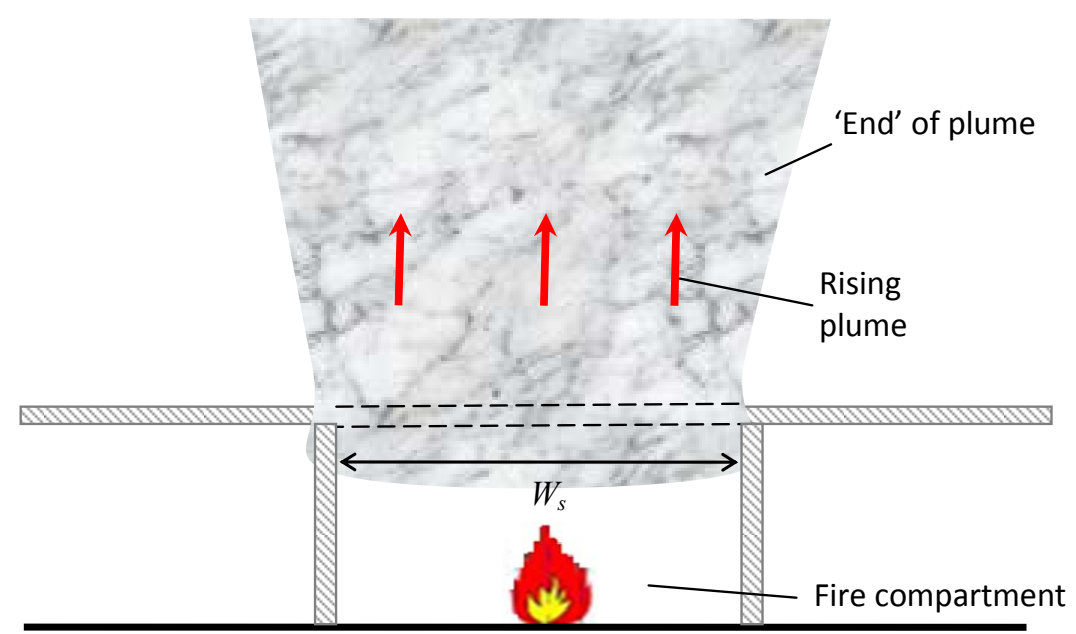

b) Front view

Figure 1: A typical adhered spill plume 

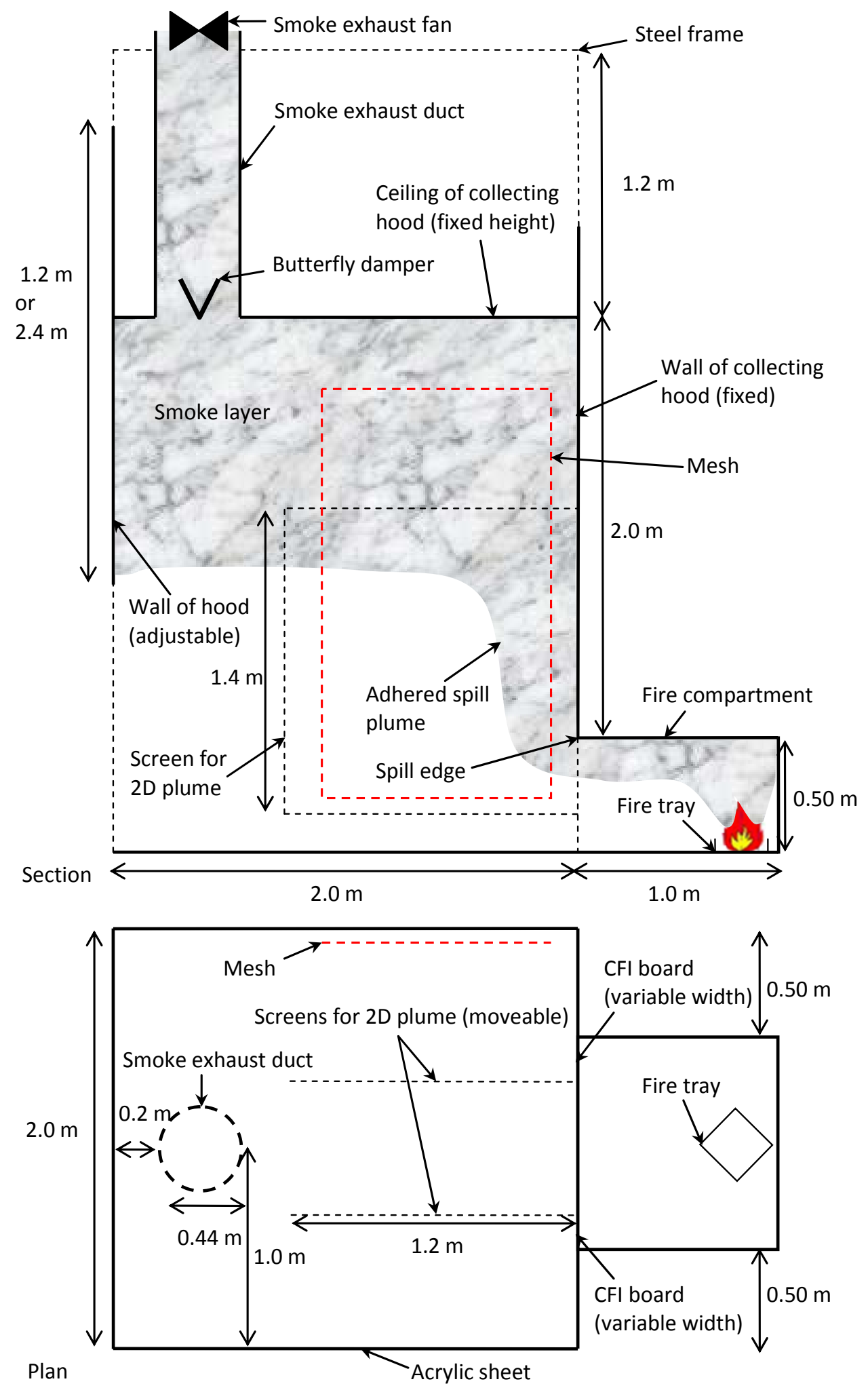

Figure 2: Schematic drawing of the $1 / 10^{\text {th }}$ physical scale model 


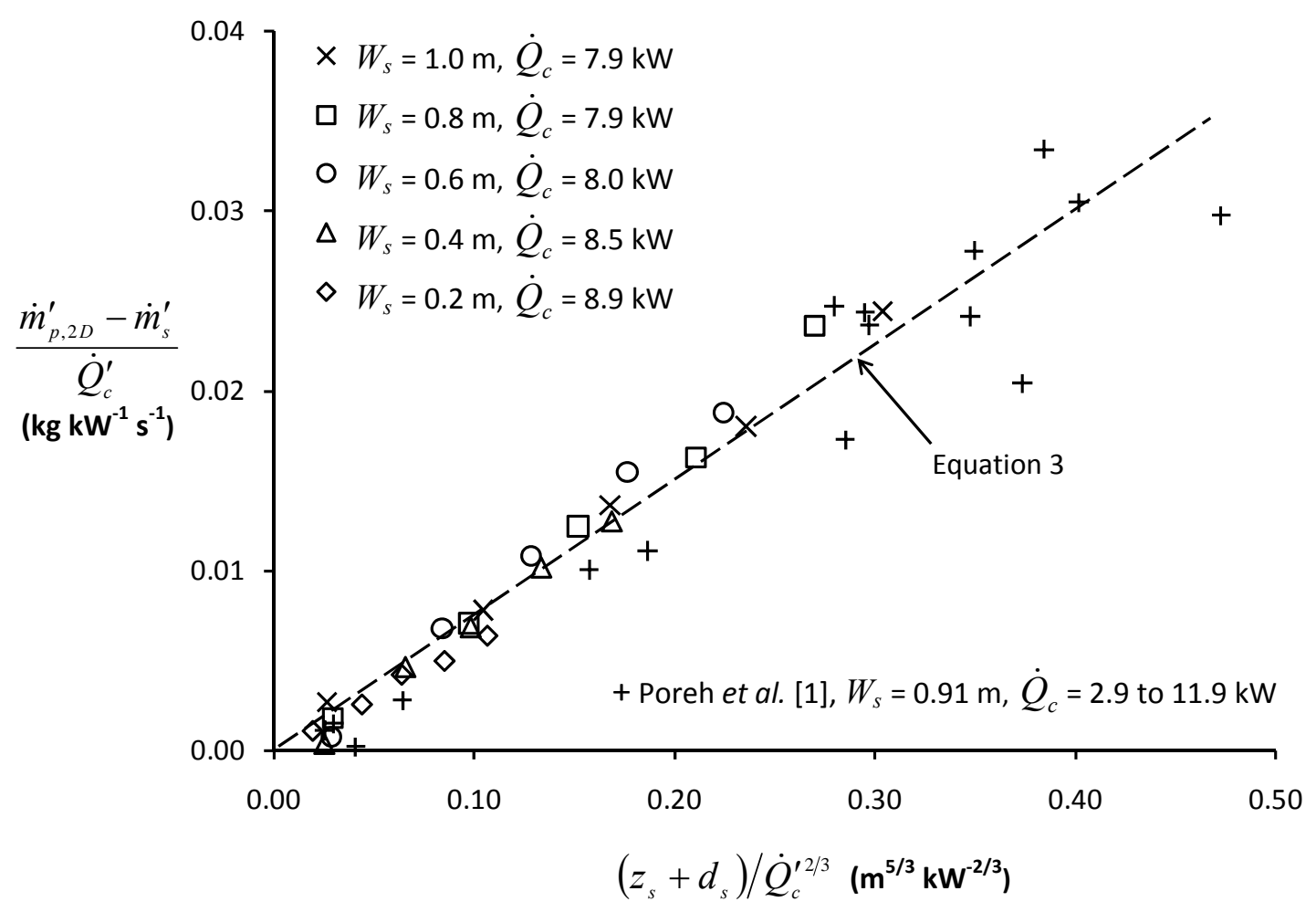

Figure 3: Experimental results for the 2-D plume according to Poreh et al. [1] 


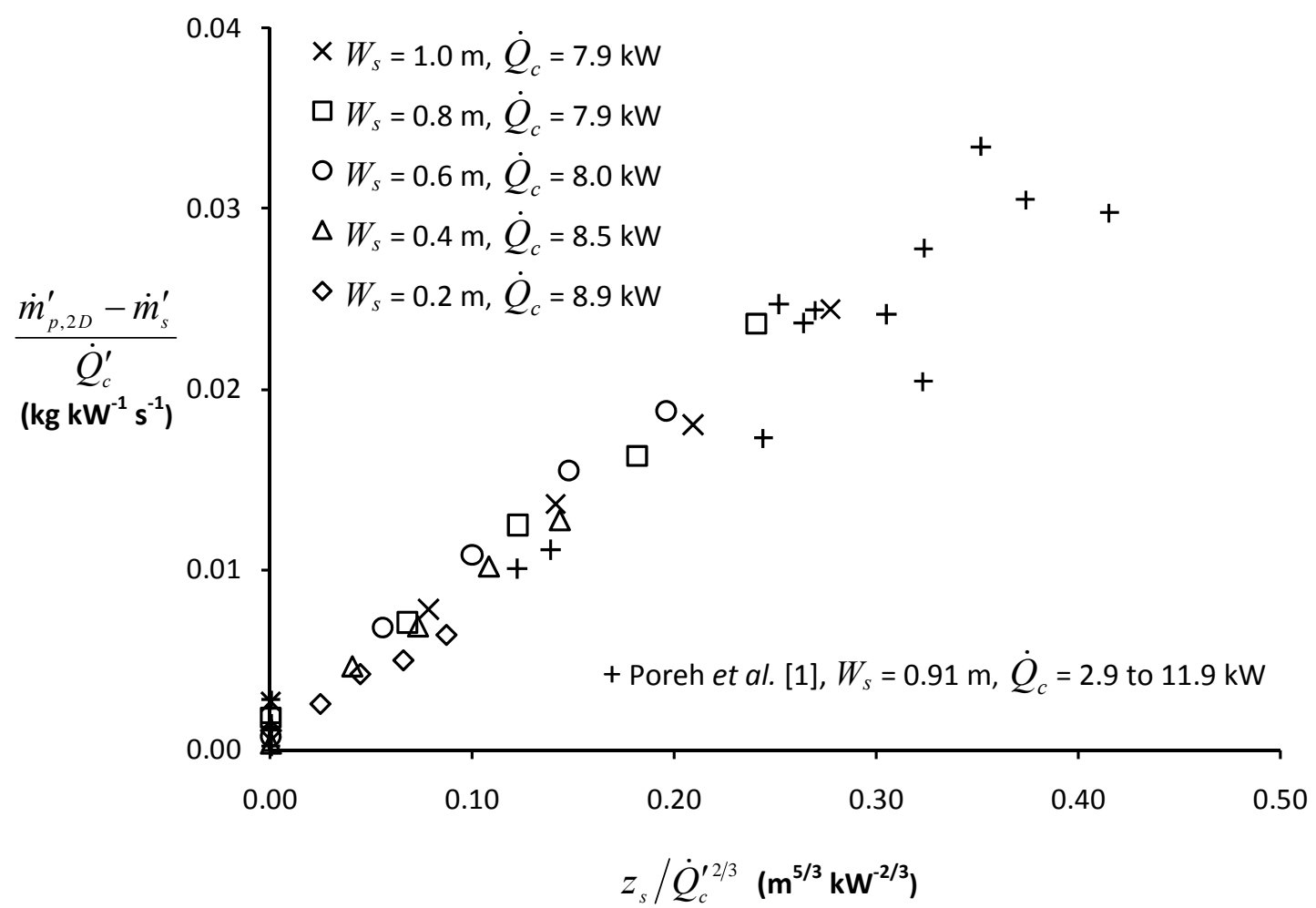

Figure 4: Entrainment results for the 2-D plume according to Thomas et al. [13] 


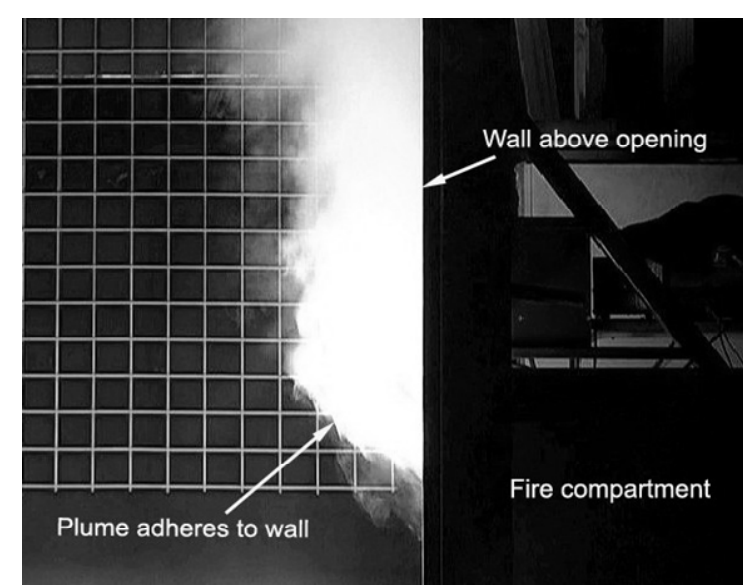

a) Side view

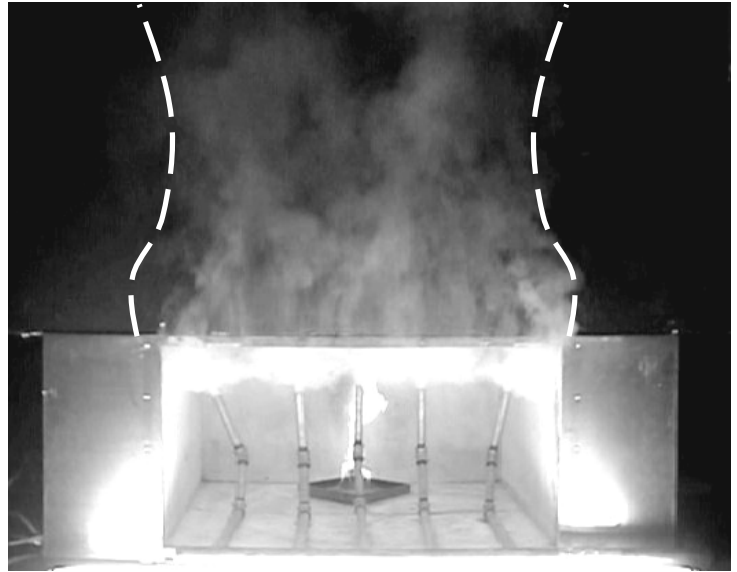

b) Front view

Figure 5: Plume behaviour $\left(W_{s}=1.0 \mathrm{~m}\right)$ 


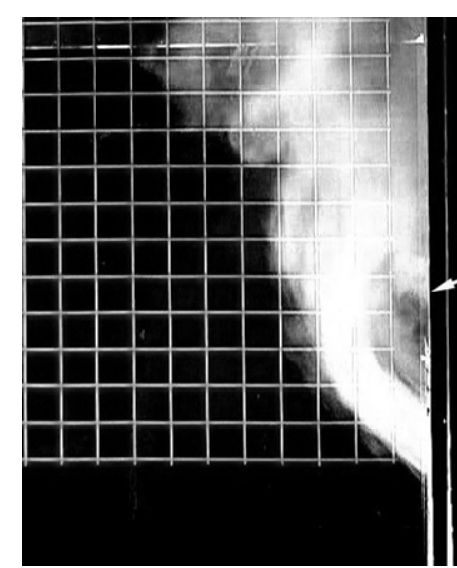

a) Side view

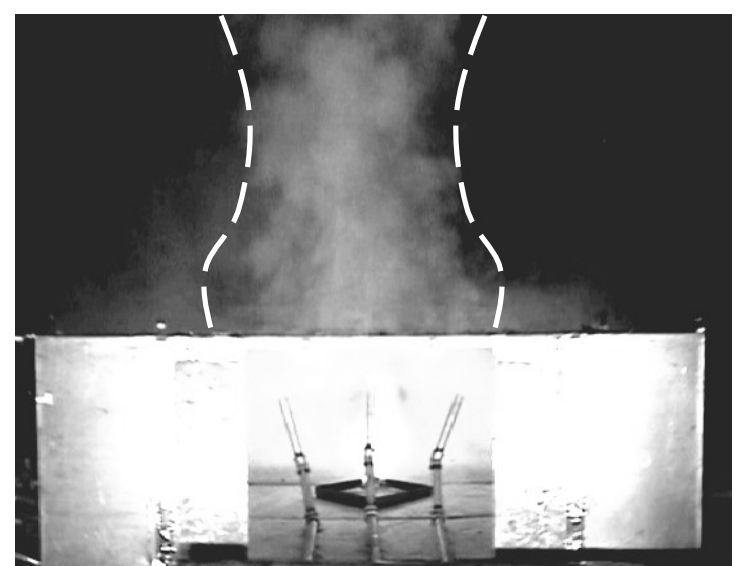

b) Front view

Figure 6: Plume behaviour $\left(W_{s}=0.6 \mathrm{~m}\right)$ 


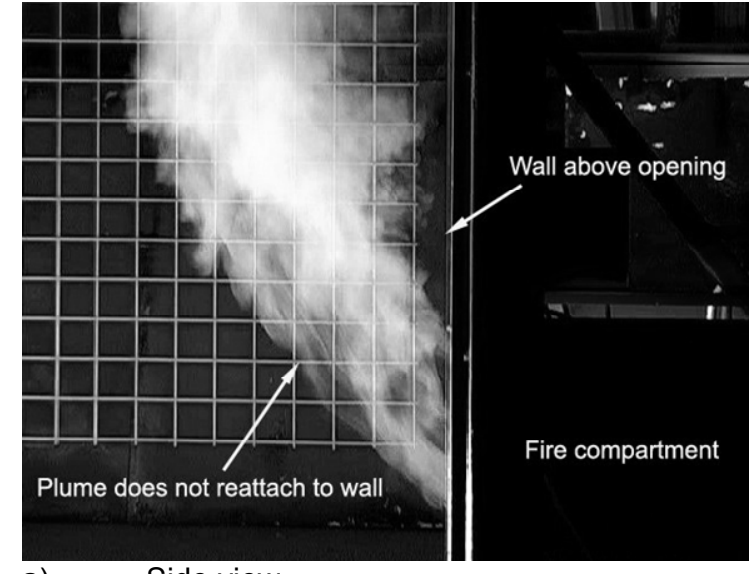

a) Side view

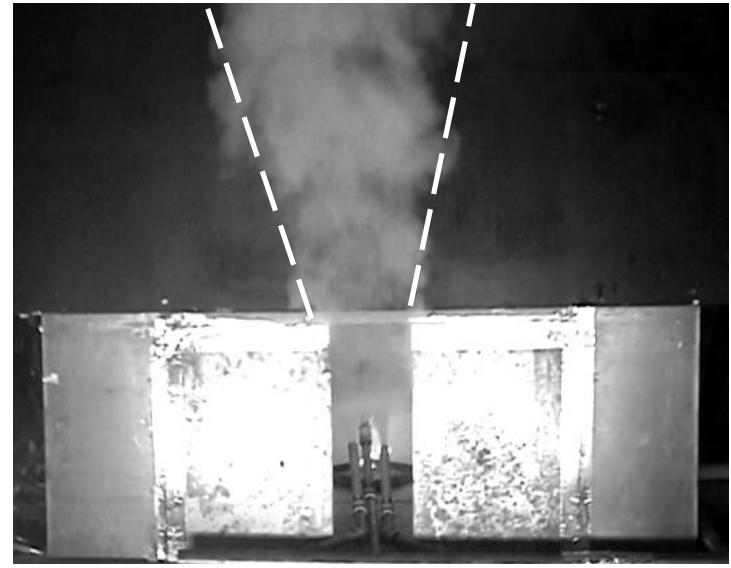

b) Front view

Figure 7: Plume behaviour $\left(W_{s}=0.2 \mathrm{~m}\right)$ 


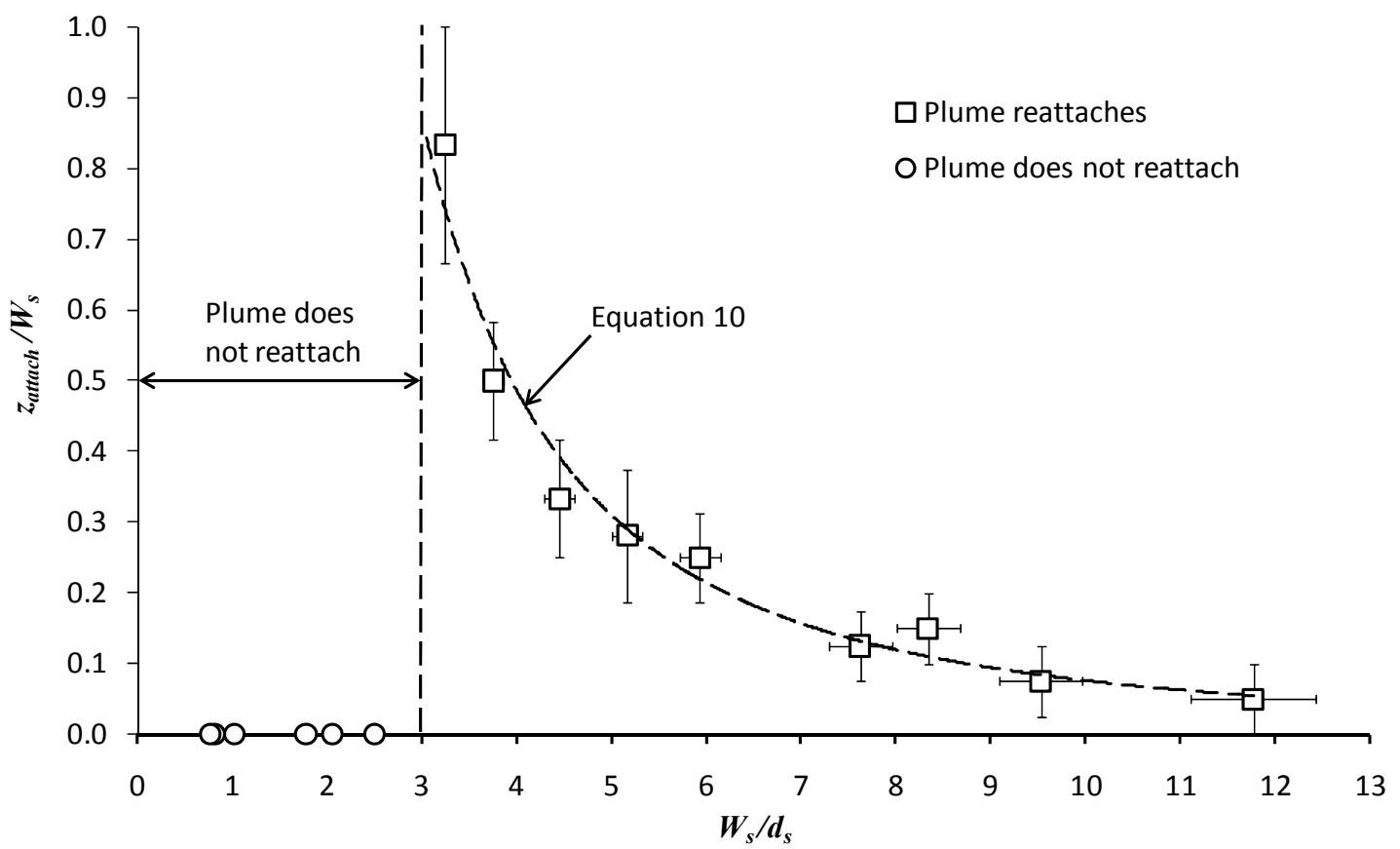

Figure 8: Plot of $z_{\text {attach }} / W_{s}$ with respect to $W_{s} / d_{s}$ 


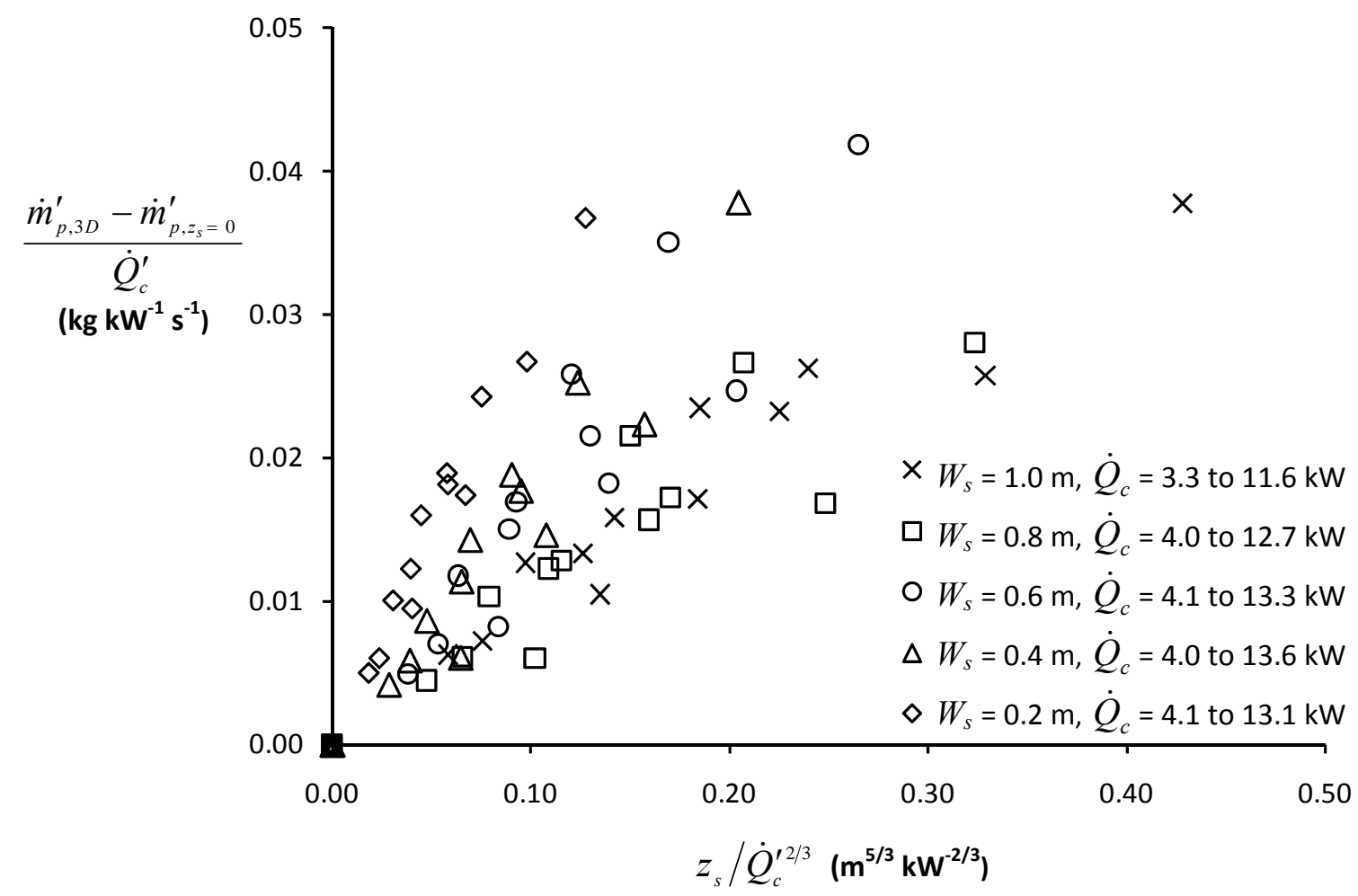

Figure 9: Decoupled entrainment above the spill edge using the Thomas et al. [13] analysis 


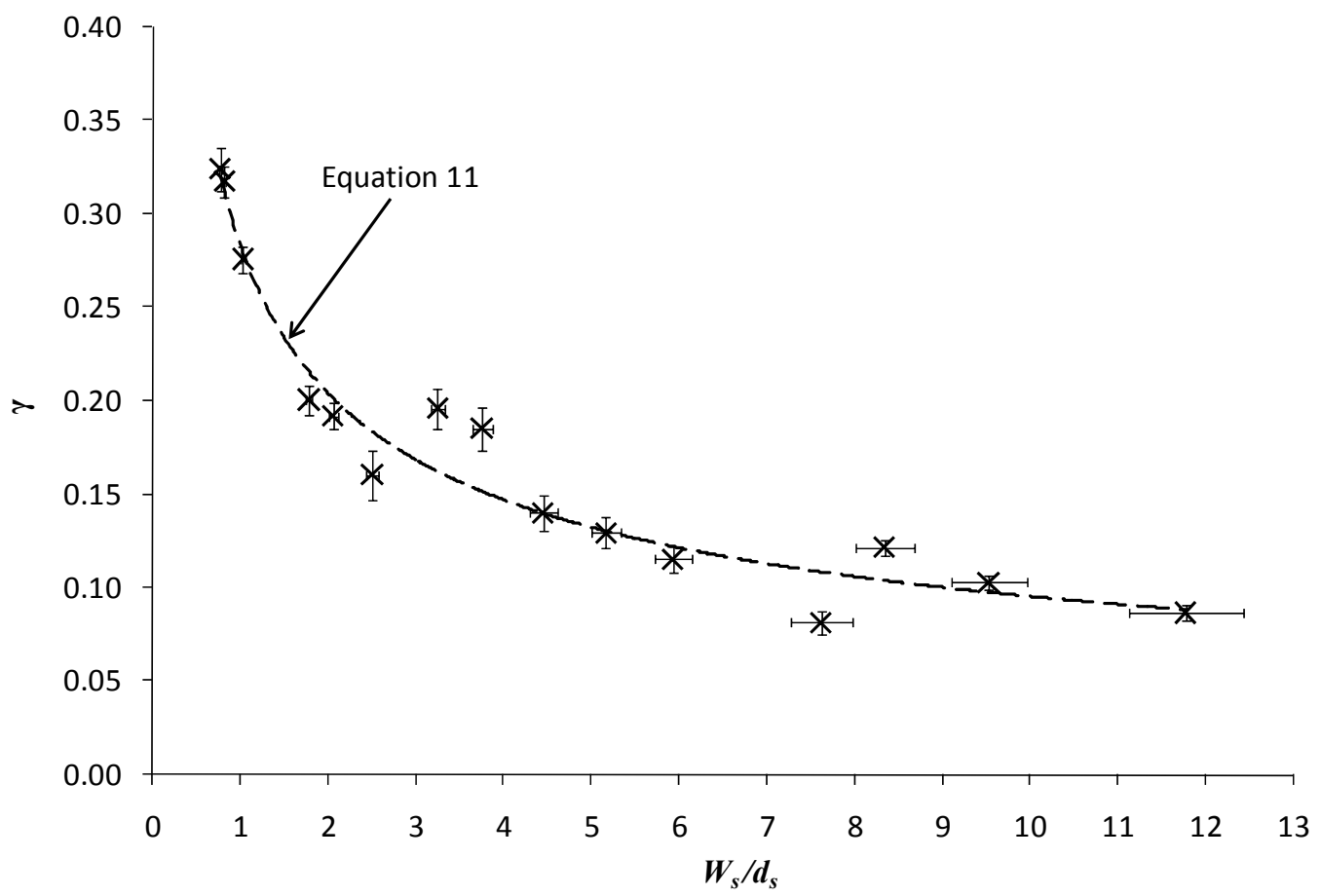

Figure 10: Plot of $\gamma$ versus $W_{s} / d_{s}$ for entrainment above the spill edge 